\title{
Arachnoid cyst
}

INSERM

\section{Source}

INSERM. (1999). Orphanet: an online rare disease and orphan drug data base. Arachnoid cyst. ORPHA:2356

Arachnoid cysts are extraparenchymal, intra-arachnoidal collections of fluid, the composition of which is close to that of cerebrospinal fluid. They are often asymptomatic. 